\title{
Low serum lycopene concentration is associated with an excess incidence of acute coronary events and stroke: the Kuopio Ischaemic Heart Disease Risk Factor Study
}

\author{
Tiina H. Rissanen ${ }^{1}$, Sari Voutilainen ${ }^{1}$, Kristiina Nyyssönen ${ }^{1}$, Timo A. Lakka ${ }^{1}$, Juhani Sivenius ${ }^{2}$, \\ Riitta Salonen ${ }^{1}$, George A. Kaplan ${ }^{3}$ and Jukka T. Salonen ${ }^{1,4} *$ \\ ${ }^{1}$ Research Institute of Public Health, University of Kuopio, PO Box 1627, FIN-70211, Kuopio, Finland \\ ${ }^{2}$ Department of Neuroscience and Neurology, University of Kuopio and Brain Research and \\ Rehabilitation Center Neuron, Kuopio, Finland \\ ${ }^{3}$ School of Public Health, University of Michigan, Ann Arbor, Michigan, 48109-2029 USA \\ ${ }^{4}$ Inner Savo Health Centre, Suonenjoki, Finland
}

(Received 16 June 2000 - Revised 18 December 2000 - Accepted 11 January 2001)

\begin{abstract}
A number of epidemiological studies have shown an association between $\beta$-carotene and the risk of cardiovascular diseases, whereas only a few studies are available concerning the association of lycopene with the risk of coronary events, and no studies have been undertaken concerning lycopene and stroke. Thus, we tested the hypothesis that low serum levels of lycopene are associated with increased risk of acute coronary events and stroke in middle-aged men previously free of CHD and stroke. The subjects were 725 men aged 46-64 years examined in 1991-3 in the Kuopio Ischaemic Heart Disease Risk Factor Study. Forty-one men had either a fatal or a non-fatal acute coronary event or a stroke by December 1997. In a Cox' proportional hazard's model adjusting for examination years, age, systolic blood pressure and three nutritional factors (serum folate, $\beta$-carotene and plasma vitamin $\mathrm{C}$ ), men in the lowest quarter of serum lycopene levels $(\leq 0.07 \mu \mathrm{mol} / \mathrm{l})$ had a $3 \cdot 3$-fold $(95 \% \mathrm{CI} 1 \cdot 7,6.4, P<0.001)$ risk of acute coronary events or stroke compared with the others. Our study suggests that a low serum level of lycopene is associated with an increased risk of atherosclerotic vascular events in middle-aged men previously free of CHD and stroke.
\end{abstract}

Lycopene: Coronary event: Stroke

Studies have shown the effect of carotenoids on chronic diseases in man. Carotenoids are fat-soluble pigments found in many fresh fruits and vegetables, and are transported in the human body by lipoproteins. Of more than 600 carotenoid compounds identified, at least forty have been isolated in foods (Gerster, 1997). Although a number of epidemiological studies have evaluated the association between $\beta$-carotene and the risk of cardiovascular diseases (Gey et al. 1993; Kardinaal et al. 1993; van Poppel, 1996; Daviglus et al. 1997; Price \& Fowkes, 1997), there has been little interest in the role of lycopene, an acyclic form of $\beta$-carotene, with regard to risk of acute coronary events and stroke. Lycopene is one of the major carotenoids in the Western diet. It is found almost exclusively in tomatoes and tomato products, although pink grapefruit, watermelon, rose hip, apricot and guava also contribute to the dietary intake of lycopene (Heinonen et al. 1989, Mangels et al. 1993). Like other carotenoids, lycopene is a natural pigment synthesized by plants and micro-organisms but not by animals (Gerster, 1997). Carotenoids have been shown to act as antioxidants (Stahl \& Sies, 1996; Clinton, 1998), and lycopene may be an even more potent antioxidant than $\alpha$ - or $\beta$-carotene (Di Mascio et al. 1989). It has been shown in vitro that lycopene in LDL is used before $\beta$-carotene, lutein, zeaxanthin or cryptoxanthin in $\mathrm{Cu}$-induced $\mathrm{LDL}$ oxidation reactions (Esterbauer et al. 1992). A decreased oxidative modification of LDL (Agarwal \& Rao, 1998) may be one of the mechanisms by which lycopene might reduce the risk of cardiovascular disease.

\footnotetext{
Abbreviation: MONICA, Monitoring of Trends and Determinants of Cardiovascular Diseases.

* Corresponding author: Professor Jukka T. Salonen, fax +358 17162 936, email jukka.salonen@uku.fi
} 
There have been no prospective population studies to observe an association between serum or tissue levels of lycopene and the risk of stroke, and only a few previous epidemiological studies have dealt with the relationship between serum or tissue lycopene levels and the risk of acute coronary events (Street et al. 1994; Kohlmeier et al. 1997). The purpose of the present study was to test the hypothesis that a low serum concentration of lycopene is associated with an increased risk of acute coronary events or stroke in middle-aged men living in eastern Finland, free of previous CHD and stroke.

\section{Materials and methods}

\section{Subjects}

The Kuopio Ischaemic Heart Disease Risk Factor Study is an ongoing population-based study designed to investigate risk factors for cardiovascular disease, atherosclerosis and related outcomes in middle-aged men from eastern Finland, the population with one of the highest recorded rates of CHD (Salonen, 1988). The study was approved by the Research Ethics Committee of the University of Kuopio. All study subjects gave their written informed consent. A total of 2682 participants (82.9 \% of those eligible), aged $42,48,54$ or 60 years, were enrolled in the study between March 1984 and December 1989. The 4-year follow-up examinations for those examined in 1987-9 were conducted between March 1991 and December 1993. Of a total of 1229 men eligible for the follow-up study, fifty-two had died, were suffering severe illness, or had migrated away from the region, and 139 could not be contacted or refused to participate. Thus, 1038 men were examined in the follow-up study. As previous disease affects the diet, men with a prevalent CHD or stroke ( $n$ 306) were excluded from the present analyses. Of the remaining 732 men, data on serum lycopene concentration were available for 725 men.

\section{Measurements}

The subjects came to give blood samples between 08.00 and 10.00 hours. They were instructed to abstain from ingesting alcohol for $3 \mathrm{~d}$, and from smoking and eating for $12 \mathrm{~h}$. For each subject, after resting in the supine position for $30 \mathrm{~min}$, blood was drawn into Terumo Venoject (Leuven, Belgium) vacuum tubes. No tourniquet was used.

Serum for lycopene and $\beta$-carotene determination was extracted with ethanol and hexane. Measurements were carried out by reversed-phase HPLC using samples that had been kept at $-80^{\circ} \mathrm{C}$ for $4-36$ months (Porkkala-Sarataho et al. 1996). Briefly, $200 \mu \mathrm{l}$ heparinized plasma was extracted with $5 \mathrm{ml}$ hexane and $1 \mathrm{ml}$ ethanol containing $\alpha$ tocopheryl acetate as an internal standard. The hexane layer was separated and evaporated to dryness. The residue was dissolved in a mobile phase. The mobile phase consisted of acetonitrile-methanol-choloroform (47:47:6, by vol.). A reversed-phase $\mathrm{C}_{18}$ column was used, and peaks were detected at wavelengths of $470 \mathrm{~nm}$ for lycopene and $454 \mathrm{~nm}$ for $\beta$-carotene by a diode array detector (Model 168; Beckman Instruments, San Ramon, CA, USA). Pure analytes from Sigma (St Louis, MO, USA) were used as primary standards and their concentrations were determined spectrophotometrically according to the method of Thurnham et al. (1988). As the stability of the pure carotenoids is poor, a frozen plasma pool was used as the secondary standard with the analysis batches. Extraction efficiency was tested by adding known amounts of lycopene standard (Sigma) and calculating the recovery. The recoveries for added lycopene were $80 \%$ for $0.45 \mu \mathrm{mol} / 1$ and $75 \%$ for $1.35 \mu \mathrm{mol} / 1$. For evaluation of the stability of lycopene, we calculated the means of the fifty-six first samples stored for 36 months $(0 \cdot 113 \mu \mathrm{mol} / \mathrm{l})$ and the fifty-six last samples $(0.110 \mu \mathrm{mol} / \mathrm{l})$ stored for 4 months. Thus, serum lycopene samples were shown to be well preserved until the measurement. The detection limit for each carotenoid with this method was $0 \cdot 03-0.07 \mu \mathrm{mol} /$ 1. The values below the detection limits of the assay batch were marked as 0.00 for the statistical analysis. The CV were determined with a serum pool analysed in twenty-five separate batches. The CV was $11.0 \%$ for lycopene and $16.2 \%$ for $\beta$-carotene. Serum folate was determined by radioimmunoassay (Bio-Rad, Hercules, CA, USA). Plasma vitamin $\mathrm{C}$ was measured 4 years earlier at the Kuopio IHD Risk Factor Study baseline visit by HPLC (Nyyssönen et al. 1997).

The main serum lipoprotein fractions, LDL-cholesterol and HDL-cholesterol, were determined from fresh serum samples using combined ultracentrifugation and precipitation, and serum cholesterol was measured enzymically (Konelab, Espoo, Finland; Salonen et al. 1991).

Resting blood pressure was measured in the morning by two trained nurses with a random-zero $\mathrm{Hg}$ sphygmomanometer (Hawksley, UK). The measuring procedures included, after supine rest for $5 \mathrm{~min}$, three measurements in the supine position, one on standing and two in the sitting position, with $5 \mathrm{~min}$ intervals between measurements. The mean of all six measurements was used as the systolic and diastolic blood pressure. BMI was computed.

The number of cigarettes, cigars and pipefuls of tobacco currently smoked daily, the duration of regular smoking (years) and the history of myocardial infarction, angina pectoris and medication were recorded on a self-administered questionnaire, which was checked by an interviewer. Repeat interviews to obtain medical history of CHD was conducted by a physician. The family history of CHD was defined as positive if at least one close relative (father, mother, sister or brother) of the subject had a history of CHD. A subject was defined as a smoker if he had ever smoked on a regular basis and had smoked cigarettes, cigars, or a pipe within the past $30 \mathrm{~d}$.

\section{Collection and classification of coronary events and strokes}

The collection of data on acute coronary events and strokes by the end of 1992 and their diagnostic classification were carried out as part of the multinational WHO (Monitoring of Trends and Determinants in Cardiovascular Diseases MONICA) project, in which detailed information of all non-fatal or fatal coronary events and strokes were collected prospectively (Tunstall-Pedoe et al. 1994). At baseline, all participants in the Kuopio IHD Risk Factor 
Study lived in the province of Kuopio, one of the monitoring areas of the Finnish part of the WHO MONICA project (Tuomilehto et al. 1992, 1996). In the Finnish part of the MONICA study, regional coronary and stroke register teams collected data on coronary events and strokes from hospitals and wards of health centres and classified the events, as explained in detail previously (Tuomilehto et al. 1992, 1996; Salomaa et al. 1997). Data on coronary events and strokes from the beginning of 1993 were obtained by computer linkage to the national hospital discharge and death registers. Coronary events were collected and classified by an internist (TAL) and strokes by a neurologist (JS) or an internist (TAL) using the same procedures as in the Finnish part of the MONICA study (Tuomilehto et al. 1992, 1996; Salomaa et al. 1997).

The diagnostic classification of acute coronary events was based on symptoms, electrocardiographic findings, cardiac enzyme elevations, autopsy findings and the history of CHD. Each suspected coronary event (ICD-9 codes 410-414 and ICD-10 codes I20-I25) was classified into: (1) a definite acute myocardial infarction; (2) a probable acute myocardial infarction; (3) a typical acute chest pain episode of more than 20 min indicating CHD; (4) an ischaemic cardiac arrest with successful resuscitation; (5) no acute coronary event; (6) an unclassifiable fatal case.

The diagnosis of stroke was based on a sudden onset of clinical signs of focal or global disturbance of cerebral function lasting more than $24 \mathrm{~h}$ (except in the cases of sudden death or if the development of symptoms was interrupted by surgical intervention) with no apparent cause other than vascular origin. Each suspected stroke (ICD-9 codes 430-438 and ICD-10 codes I60-I68 and G45-G46) was classified into: (1) a definite stroke; (2) no stroke; (3) an unclassifiable event. Each definite stroke was classified into: (1) an ischaemic stroke (ICD-9 codes 433-434, ICD10 code I63); (2) a haemorrhagic stroke (ICD-9 codes 430431, ICD-10 codes I60-I61).

In the present study, definite or probable acute myocardial infarctions, prolonged chest pain episodes and definite ischaemic strokes were used as outcome events. If a subject had multiple non-fatal coronary events or strokes during the follow-up, the first was considered the end point. The average follow-up time to the first coronary event or stroke was 5.3 (range 0.4-6.9) years. Of all forty-one outcome events, nineteen were definite and ten were probable acute myocardial infarctions, four were typical acute chest pain episodes and eight were ischaemic strokes.

\section{Statistical methods}

Data were analysed using SPSS 9.01 for Windows 98 (SPSS Inc., Chicago, IL, USA). The distributions were expressed as means and ranges. The means were compared by ANOVA. The subjects were classified into quarters according to their serum lycopene concentrations. The relationship between serum lycopene concentration and the risk of acute coronary events and strokes was analysed using Cox' proportional hazard's models. Relative hazards (risks), adjusted for other risk factors, were estimated as antilogarithms of coefficients for independent variables. The CI were estimated on the assumption of asymptotic normality of estimates. All statistical tests were two-tailed.

\section{Results}

The mean serum lycopene concentration was $0 \cdot 17$ (SD $0 \cdot 14$ ) $\mu \mathrm{mol} / \mathrm{l}$, ranging from none to $1.02 \mu \mathrm{mol} / \mathrm{l}$. Men who developed an acute coronary event or stroke had a $39 \%$ lower $(P=0.003)$ serum level of lycopene, a lower plasma level of vitamin $C(P=0.018)$ and a higher systolic blood pressure $(P=0.039)$ than the other men. In addition, they were older $(P=0 \cdot 011)$. The baseline characteristics of the cohort members are shown in Table 1.

The risk of acute coronary events or stroke decreased on average by $4 \%$ for each increment in serum lycopene concentration of $0.01 \mu \mathrm{mol} / \mathrm{l}$. We categorised the subjects into quarters of the serum level of lycopene $(\leq 0.07$, $0.08-0 \cdot 14,0.15-0.24$ and $>0.24 \mu \mathrm{mol} / \mathrm{l})$ and compared the lowest quarter with the other quarters. Age, systolic blood pressure, BMI, serum folate, $\beta$-carotene and plasma vitamin $\mathrm{C}$ differed statistically significantly between the quarters (Table 2). During the average follow-up time of 5

Table 1. The main characteristics of the subjects participating in the study*

(Mean values and standard deviations)

\begin{tabular}{|c|c|c|c|c|c|c|c|}
\hline & \multicolumn{2}{|c|}{$\begin{array}{l}\text { Subjects who developed } \\
\text { an acute coronary } \\
\text { event or a stroke }(n 41)\end{array}$} & \multicolumn{2}{|c|}{$\begin{array}{l}\text { Other subjects } \\
\quad(n \text { 684) }\end{array}$} & \multirow{2}{*}{$\begin{array}{l}\text { Statistical significance } \\
\text { of difference } \\
\text { between means: } P\end{array}$} & \multicolumn{2}{|c|}{ All subjects $(n 725)$} \\
\hline & Mean & SD & Mean & SD & & Mean & SD \\
\hline Serum lycopene $(\mu \mathrm{mol} / \mathrm{l})$ & $0 \cdot 10$ & 0.12 & 0.17 & 0.14 & 0.003 & 0.17 & 0.14 \\
\hline Serum $\beta$-carotene $(\mu \mathrm{mol} / \mathrm{l})$ & 0.42 & 0.41 & 0.41 & 0.33 & 0.839 & 0.41 & 0.33 \\
\hline Serum folate $(\mathrm{nmol} / \mathrm{l})$ & $9 \cdot 77$ & $4 \cdot 30$ & $10 \cdot 48$ & 3.90 & 0.258 & $10 \cdot 44$ & 3.92 \\
\hline Plasma vitamin $\mathrm{C}(\mathrm{mg} / \mathrm{l}) \dagger$ & 7.82 & 3.93 & $9 \cdot 26$ & $3 \cdot 77$ & 0.018 & $9 \cdot 17$ & 3.79 \\
\hline Age (years) & 57.6 & 6.5 & $54 \cdot 9$ & $6 \cdot 6$ & 0.011 & $55 \cdot 0$ & $6 \cdot 6$ \\
\hline $\mathrm{BMl}\left(\mathrm{kg} / \mathrm{m}^{2}\right)$ & $27 \cdot 6$ & 3.5 & $27 \cdot 4$ & 3.5 & 0.721 & $27 \cdot 4$ & 3.5 \\
\hline Systolic blood pressure $(\mathrm{mmHg})$ & $140 \cdot 1$ & $15 \cdot 1$ & 134.6 & $16 \cdot 4$ & 0.039 & 134.9 & $16 \cdot 4$ \\
\hline Serum cholesterol (mmol/l): Total & 5.69 & 0.85 & 5.50 & 0.91 & 0.178 & 5.51 & 0.91 \\
\hline HDL & 1.08 & 0.29 & 1.12 & 0.29 & 0.350 & 1.12 & 0.29 \\
\hline LDL & $4 \cdot 10$ & 0.75 & 3.90 & 0.81 & 0.132 & 3.91 & 0.81 \\
\hline Smoking (\%) & 34 & & 27 & & 0.315 & 27 & \\
\hline
\end{tabular}

${ }^{*}$ For details of experimental procedures, see p.750.

† Measured 4 years earlier. 
Table 2. The characteristics (mean) of the subjects classified into quarters by serum lycopene concentration*

\begin{tabular}{|c|c|c|c|c|c|}
\hline & \multicolumn{4}{|c|}{ Quarter of serum lycopene concentration $(\mu \mathrm{mol} / \mathrm{l})$} & \multirow{2}{*}{$\begin{array}{l}P \text { value for } \\
\text { heterogeneity }\end{array}$} \\
\hline & $\leq 0.07$ & $0.08-0.14$ & $0.15-0.24$ & $>0.24$ & \\
\hline Serum lycopene $(\mu \mathrm{mol} / \mathrm{l})$ & 0.01 & $0 \cdot 11$ & $0 \cdot 19$ & 0.36 & \\
\hline Serum $\beta$-carotene $(\mu \mathrm{mol} / \mathrm{l})$ & 0.32 & 0.40 & 0.40 & 0.51 & $<0.001$ \\
\hline Serum folate $(\mathrm{nmol} / \mathrm{l})$ & 9.63 & $10 \cdot 09$ & $10 \cdot 88$ & $11 \cdot 17$ & $<0.001$ \\
\hline Plasma vitamin $\mathrm{C}(\mathrm{mg} / \mathrm{l}) \dagger$ & $8 \cdot 10$ & 8.95 & $9 \cdot 82$ & $9 \cdot 85$ & $<0.001$ \\
\hline Age (years) & $57 \cdot 1$ & $56 \cdot 4$ & $53 \cdot 9$ & $52 \cdot 7$ & $<0.001$ \\
\hline Systolic blood pressure $(\mathrm{mmHg})$ & $138 \cdot 1$ & $136 \cdot 7$ & $132 \cdot 9$ & $132 \cdot 0$ & 0.001 \\
\hline BMI $\left(\mathrm{kg} / \mathrm{m}^{2}\right)$ & $27 \cdot 7$ & $27 \cdot 6$ & $27 \cdot 5$ & $26 \cdot 8$ & 0.048 \\
\hline Serum cholesterol $(\mathrm{mmol} / \mathrm{l})$ Total & 5.49 & 5.53 & 5.43 & 5.59 & 0.384 \\
\hline LDL & 3.90 & 3.89 & $3 \cdot 86$ & 4.01 & 0.289 \\
\hline $\mathrm{HDL}$ & $1 \cdot 12$ & $1 \cdot 10$ & $1 \cdot 11$ & $1 \cdot 14$ & 0.712 \\
\hline Smoking (\%) & 32 & 25 & 26 & 26 & 0.424 \\
\hline $\begin{array}{l}\text { No. of subjects who developed an acute } \\
\text { myocardial infarction or a stroke }\end{array}$ & $23(12.6 \%)$ & $5(2 \cdot 8 \%)$ & $8(4.3 \%)$ & $5(2.9 \%)$ & $<0.001$ \\
\hline
\end{tabular}

* For details of experimental procedures, see p.750.

$\uparrow$ Measured 4 years earlier.

years and 3 months, eighteen men $(9.7 \%)$ in the lowest quarter and fifteen men $(2.8 \%)$ in other quarters jointly developed an acute coronary event $(P<0.001)$ and five men $(2.7 \%)$ in the lowest quarter and three men $(0.6 \%)$ in the other quarters developed a stroke $(P=0 \cdot 016)$. In a Cox' proportional hazard's model adjusting for age, examination years, systolic blood pressure and three nutritional factors (serum $\beta$-carotene, folate and plasma vitamin $\mathrm{C}$ ), men in the lowest quarter of serum concentration of lycopene had a 3.3-fold (95\% CI 1.7, 6.4; $P<$ $0.001)$ risk of an acute coronary event or stroke as compared with the others $(P=0.009$ for a linear trend across the quarters, $P=0.027$ for a linear trend in a continuous variable). We repeated similar analyses for acute coronary events alone. The adjusted relative risk for acute coronary events among men in the lowest quarter of serum level of lycopene was 2.8 (95\% CI $1.4,5 \cdot 7, P=$ 0.005 , and $P=0.055$ for a linear trend across the quarters).

The mean serum concentration of $\beta$-carotene was 0.41 (SD 0.33 ) $\mu \mathrm{mol} / 1$, ranging from 0 to $4.33 \mu \mathrm{mol} / 1$. We categorised the subjects into quarters based on the serum level of $\beta$-carotene $(\leq 0.23,0.24-0.34,0.35-0.49$ and $>0.49 \mu \mathrm{mol} / \mathrm{l})$ and compared the lowest quarter with the others. There was no statistically significant association between serum concentration of $\beta$-carotene and the risk of acute coronary event or stroke.

\section{Discussion}

In this prospective population-based study we found an inverse association between serum lycopene concentration and the risk of acute coronary events or stroke. This association was strong and other cardiovascular risk factors, including the major plant-derived protective dietary factors did not explain this association.

The association between blood or tissue lycopene concentration and CHD has been studied previously in only a few studies (Street et al. 1994; Howard et al. 1996; Iribarren et al. 1997; Kohlmeier et al. 1997; KlipsteinGrobusch et al. 2000). In a nested case-control study (Street et al. 1994), low serum levels of $\beta$-carotene, lycopene, lutein and zeaxanthin were associated with an increased risk of subsequent myocardial infarction in smokers, but not in non-smokers. In the cross-sectional multicentre EURAMIC study (Kohlmeier et al. 1997), subjects who had undergone a myocardial infarction had lower adipose tissue lycopene concentrations than the controls. In the Rotterdam study (Klipstein-Grobusch et al. 2000) the serum level of lycopene was inversely associated with aortic calcification, and this association was most pronounced in current and former smokers. No association with risk of aortic calcification was observed for the other serum carotenoids $\alpha$-carotene, $\beta$-carotene, lutein and zeaxanthin. Howard et al. (1996) speculated that the lower incidence of $\mathrm{CHD}$ in Toulouse than in Belfast could be partly due to the significantly higher plasma $\alpha$ carotene concentrations in Toulouse, but they found no association with plasma lycopene concentration and the incidence of CHD. In the Atherosclerosis Risk in Communities study (Iribarren et al. 1997), both serum $\alpha$-carotene and lycopene concentrations had a non-significant inverse association with carotid artery intima-media thickness, whereas serum $\beta$-carotene was not related to intima-media thickness. Our finding provides further evidence for the hypothesis that low serum lycopene concentrations are associated with increased risk of acute coronary events.

There are no earlier studies of the association between serum level of lycopene and the risk of stroke. In the prospective Health Professionals Study (Asherio et al. 1999), a high dietary intake of lutein was associated with a reduced risk for ischaemic stroke, whereas the dietary intake of lycopene or $\alpha$ - or $\beta$-carotene had no association with the stroke risk.

The mean serum concentration of lycopene in our study was lower, whereas the mean serum level of $\beta$-carotene was approximately the same, when compared with serum or plasma levels in other studies (Howard et al. 1996; Iribarren et al. 1997; Kristenson et al. 1997; Paetau et al. 1999). In the multicentre EURAMIC study the lowest adipose tissue concentrations of lycopene were found in Helsinki and in Malaga, whereas the $\beta$-carotene level in adipose tissue was the same in Helsinki as it was in other 
northwest European countries (Kohlmeier et al. 1997). We did not find any statistically significant association between serum $\beta$-carotene concentration and the risk of acute coronary events and stroke.

The oxidative modification of LDL particles may have a role in the formation of foam cells, atherosclerotic lesions and CHD (Salonen et al. 1992; Witztum \& Hörkkö, 1997). Antioxidants can inhibit the oxidative modification of LDL, and may retard atherosclerotic progression and consequently prevent clinical complications of atherosclerosis such as myocardial infarction (Diaz et al. 1997; Salonen 1998). Lycopene and other carotenoids have been shown to act as antioxidants (Stahl \& Sies, 1996; Agarwal \& Rao, 1998; Clinton, 1998). Thus, carotenoids found in plasma can quench singlet oxygen, a potential initiator of lipid peroxidation (Clinton, 1998). Lycopene, the openchain isomer of $\beta$-carotene, exhibits the highest physical quenching rate constant with singlet oxygen of all major carotenoids (Di Mascio et al. 1989).

There are a few limitations in our study. First, our follow-up period was quite short (5 years and 3 months) and we had a limited number of outcome events. Serum lycopene is a biomarker of lycopene intake. During a longer follow-up period, diet could have changed and attenuated the association between dietary biomarkers and diseases. However, the association was similar when using a follow-up time of either 4.3 or 5.3 years. There are also other prospective studies in which the follow-up times have been the same as or even shorter than that of our study (Folsom et al. 1998; Klipstein-Grobusch et al. 1999).

In the present study, subjects were 46-64 years of age, which is very similar to the age range in other prospective cohort studies (Folsom et al. 1998; Liu et al. 1999). Men with prevalent CHD or stroke were excluded from the present analyses. If the subjects had been older, more of them would have had prevalent disease and, thus, would have been excluded from the analyses.

Second, we cannot fully exclude the possibility that part of the observed association reflects confounding by other dietary and lifestyle factors associated with a reduced risk of CHD and cerebrovascular disease. However, serum concentrations of $\beta$-carotene and folate, and plasma concentration of vitamin $\mathrm{C}$, also markers of a healthy diet, did not confound these associations.

In conclusion, our results are consistent with a protective effect of lycopene on the risk of acute coronary events or stroke in middle-aged men living in eastern Finland. If confirmed, these findings suggest that lycopene, presumably a biomarker of a tomato-rich diet, might have a role in the prevention of cardiovascular diseases.

\section{Acknowledgements}

We are grateful to our staff of almost forty individuals for helping with data collection, to Professor Jaakko Tuomilehto and Professor Kalevi Pyörälä for access to the FINMONICA registry data and to Sudhir Kurl for useful comments. This study was supported by grants from the Juho Vainio Foundation, the Academy of Finland and the NHLBI of the USA. K.N. is a research scientist of the Academy of Finland.

\section{References}

Agarwal S \& Rao AV (1998) Tomato lycopene and low density lipoprotein oxidation: A human dietary intervention study. Lipids 33, 981-984.

Ascherio A, Rimm EB, Hernán MA, Giovannucci E, Kawachi I, Stampfer MJ \& Willett WC (1999) Relation of consumption of vitamin $\mathrm{E}$, vitamin $\mathrm{C}$, and carotenoids to risk for stroke among men in the United States. Annals of Internal Medicine 130, 963-970.

Clinton SK (1998) Lycopene: Chemistry, biology, and implications for human health and disease. Nutrition Reviews 56, 35-51.

Daviglus ML, Orencia AJ, Dyer AR, Liu K, Morris DK, Persky V, Chavez N, Goldberg J, Drum M, Shekelle RB \& Stamler J (1997) Dietary vitamin C, beta-carotene and 30-year risk of stroke: results from the Western Electric Study. Neuroepidemiology 16, 69-77.

Diaz MN, Frei B, Vita JA \& Keaney JF Jr (1997) Antioxidants and atherosclerotic heart disease. New England Journal of Medicine 337, 408-416.

Di Mascio P, Kaiser S \& Sies H (1989) Lycopene as the most efficient biological carotenoid singlet oxygen quencher. Archives of Biochemistry and Biophysics 274, 532-538.

Esterbauer H, Gebicki J, Puhl H \& Jürgens G (1992) The role of lipid peroxidation and antioxidants in oxidative modification of LDL. Free Radical Biology and Medicine 13, 341-390.

Folsom AR, Nieto FJ, McGovern PG, Tsai M, Malinow R, Eckfeldt JH, Hess DL \& Davis CE (1998) Prospective study of coronary heart disease incidence in relation to total homocysteine, related genetic polymorphism, and B vitamins. Circulation 98, 204-210.

Gerster H (1997) The potential role of lycopene for human health. Journal of the American College of Nutrition 2, 109-126.

Gey KF, Stahelin HB \& Eichholzer M (1993) Poor plasma status of carotene and vitamin $\mathrm{C}$ is associated with higher mortality from ischemic heart disease and stroke: Basel Prospective Study. Clinical Investigation 71, 3-6.

Heinonen MI, Ollikainen V, Linkola EK, Varo PT \& Koivistoinen PE (1989) Carotenoids in Finnish foods: vegetables, fruits, and berries. Journal of Agricultural and Food Chemistry 337, 655-659.

Howard AN, Williams NR, Palmer CR, Cambou JP, Evans AE, Foote JW, Marques-Vidal P, McCrum EE, Ruidavets JB, Nigdikar SV, Rajput-Williams J \& Thurnham DI (1996) Do hydroxy-carotenoids prevent coronary heart disease? A comparison between Belfast and Toulouse. International Journal for Vitamin and Nutrition Research 66, 113-118.

Iribarren C, Folsom AR, Jacobs DR, Cross MD, Belcher JD \& Eckfeldt JH (1997) Association of serum vitamin levels, LDL susceptibility to oxidation, and autoantibodies against MDALDL with carotid atherosclerosis. Arteriosclerosis, Thrombosis and Vascular Biology 17, 1171-1177.

Kardinaal AFM, Kok FJ, Ringstad J, Gomez-Aracena J, Mazaev VP, Kohlmeier L, Martin BC, Aro A, Kark JD, Delgado-Rodriquez M, Riemersma RA, van't Veer P, Huttunen JK \& Martin-Moreno JM (1993) Antioxidants in adipose tissue and risk of myocardial infarction: the EURAMIC study. Lancet 342, 1379-1384.

Klipstein-Grobusch K, Geleijnse JM, den Breeijen JH, Boeing H, Hofman A, Grobbee DE \& Witteman JC (1999) Dietary antioxidants and risk of myocardial infarction in the elderly: the Rotterdam Study. American Journal of Clinical Nutrition 69, 261-266.

Klipstein-Grobusch K, Launer LJ, Geleijnse JM, Boeing H, Hofman A \& Witteman JC (2000) Serum carotenoids and 
atherosclerosis. The Rotterdam Study. Atherosclerosis 148, 49-56.

Kohlmeier L, Kark JD, Gomez-Cracia E, Martin BC, Steck SE, Kardinaal AFM, Ringstad J, Thamm M, Masaev V, Riemersma R, Martin-Moreno JM, Huttunen JK \& Kok FJ (1997) Lycopene and myocardial risk in the EURAMIC study. American Journal of Epidemiology 146, 618-626.

Kristenson M, Zieden B, Kucinskienë Z, Schäfer Elinder L, Bergdahl B, Elwing B, Abaravicius A, Razinkovienë L, Calkauskas H \& Olsson AG (1997) Antioxidant state and mortality from coronary heart disease in Lithuanian and Swedish men: concomitant cross sectional study of men aged 50. British Medical Journal 14, 629-633.

Liu S, Stampfer MJ, Hu FB, Giovannucci E, Rimm E, Manson JAE, Hennekens CH \& Willett WC (1999) Wholegrain consumption and risk of coronary heart disease: results from the Nurses' Health Study. American Journal of Clinical Nutrition 70, 412-419.

Mangels AR, Holden JM, Beecher GR, Forman MR \& Lanza E (1993) Carotenoid content of fruits and vegetables: An evaluation of analytic data. Journal of the American Dietetic Association 93, 284-296.

Nyyssönen K, Parviainen MT, Salonen R, Tuomilehto J \& Salonen JT (1997) Vitamin C deficiency and risk of myocardial infarction: prospective population study of men from eastern Finland. British Medical Journal 314, 634-638.

Paetau I, Rao D, Wiley ER, Brown ED \& Clevidence BA (1999) Carotenoids in human mucosa cells after 4 wk of supplementation with tomato juice or lycopene supplements. American Journal of Clinical Nutrition 70, 490-494.

Porkkala-Sarataho E, Nyyssönen K \& Salonen JT (1996) Increased oxidation resistance of atherogenic plasma lipoproteins at high vitamin E levels in non-vitamin E supplemented men. Atherosclerosis 124, 83-94.

Price JF \& Fowkes FGR (1997) Antioxidant vitamins in the prevention of cardiovascular disease. The epidemiological evidence. European Heart Journal 18, 719-727.

Salomaa V, Dobson A, Miettinen H, Rajakangas A-M \& Kuulasmaa K (1997) Mild myocardial infarction - a classification problem in epidemiologic studies. WHO MONICA Project. Journal of Clinical Epidemiology 50, 3-13.

Salonen JT (1988) Is there a continuing need for longitudinal epidemiologic research? The Kuopio Ischaemic Heart Disease Risk Factor Study. Annals of Clinical Research 20, 46-50.

Salonen JT (1998) Epidemiological studies on antioxidant, lipid peroxidation and atherosclerosis. Archives of Toxicology Suppl.20, 249-267.

Salonen JT, Salonen R, Seppänen K, Rauramaa R \& Tuomilehto J (1991) HDL, $\mathrm{HDL}_{2}$, and $\mathrm{HDL}_{3}$ subfractions, and the risk of acute myocardial infarction. A prospective population study in eastern finnish men. Circulation 84, 129-139.

Salonen JT, Ylä-Herttuala S, Yamamoto R, Butler S, Korpela H, Salonen R, Nyyssönen K, Palinski W \& Witztum JL (1992) Autoantibody against oxidised LDL and progression of carotid atherosclerosis. Lancet 339, 883-887.

Stahl W \& Sies H (1996) Lycopene: A biologically important carotenoid for humans? Archives of Biochemistry and Biophysics 336, 1-9.

Street DA, Comstock GW, Salkeld RM, Schüep W \& Klag MJ (1994) Serum antioxidants and myocardial infarction. Are low levels of carotenoids and $\alpha$-tocopherol risk factors for myocardial infarction? Circulation 90, 1154-1161.

Thurnham D, Smith E \& Flora PS (1988) Concurrent liquidchromatographic assay of retinol, $\alpha$-tocopherol, $\beta$-carotene, $\alpha$ carotene, lycopene and $\beta$-cryptoxanthin in plasma, with tocopherol acetate as internal standard. Clinical Chemistry 34, 377-381.

Tunstall-Pedoe H, Kuulasmaa K, Amoyel P, Arveiler D, Rajakangas A-M \& Pajak A (1994) Myocardial infarction and coronary deaths in the World Health Organization MONICA Project: registration procedures, event rates and case fatality rates in 38 populations from 21 countries in 4 continents. Circulation 90, 583-612.

Tuomilehto J, Arstila M, Kaarsalo E, Kankaanpää J, Ketonen M, Kuulasmaa K, Lehto S, Miettinen H, Mustaniemi H, Palomäki P, Puska P, Pyörälä K, Salomaa V, Torppa J \& Vuorenmaa T (1992) Acute myocardial infarction (AMI) in Finland - baseline data from the FINMONICA AMI register in 1983-1985. European Heart Journal 13, 577-587.

Tuomilehto J, Rastenyte D, Sivenius J, Sarti C, Immonen-Räihä P, Kaarsalo E, Kuulasmaa K, Narva EV, Salomaa V, Salmi K \& Torppa J (1996) Ten-year trends in stroke incidence and mortality in the FINMONICA stroke study. Stroke 27, 825-832.

van Poppel G (1996) Epidemiological evidence for $\beta$-carotene in prevention of cancer and cardiovascular disease. European Journal of Clinical Nutrition 50, S57-S61.

Witztum JL, Hörkkö S, (1997) The role of oxidised LDL in atherogenesis: immunological response and anti-phospholipid antibodies. Annals of the New York Academy of Sciences $\mathbf{8 1 1}$, 88-96. 